\title{
A Case Study of Usability Design Principle in Responsive e-Commerce Web Application
}

\author{
Lalita Santiworarak*, Worasit Choochaiwattana \\ College of Creative Design and Entertainment Technology, Dhurakij Pundit University, Bangkok, Thailand. \\ * Corresponding author. Tel.: +66837543737; email: lalita.san@dpu.ac.th \\ Manuscript submitted June 5, 2017; accepted December 5, 2017. \\ doi: 10.17706/ijeeee.2018.8.3.139-144
}

\begin{abstract}
World is change to digital age and people life style have changed too. Online purchases also change with the changing technology as well. Now, people can shop all time and every place with their devices such as laptop, personal computer, mobile phone, tablet and another devices which can access internet. So, e-commerce website is very important to communicate between online customer and seller because of it is a key for successful in business. This paper aim to study of e-commerce web application design which using usability design principle and responsive design by developing e-commerce web application which 3 main features consist of online catalog, shopping cart and payment method which help customer to access e-commerce web application easily. Furthermore, the result of this article assist website designer and developer to consider their design that supported various customer devices.
\end{abstract}

Key words: Usability, web design, responsive, e-commerce, website.

\section{Introduction}

Today, Technology is highly impact to people in the world, for example, e-commerce website is online shopping website which easy to sales or buy something on the internet. Customers can buy 24 hours and every places which can access the internet. Moreover, website design is very important for the customers because of if the customers can access the site, they should spent their money in your shop. In this way, web developer should considering in website design which it should easy to access information and product. Usability and responsive design are the way to help them. Usability is the principle of website design and have objective to how to access website easily. User can search something on the site and find anything rapidly. Responsive design is a principle that supported difference devices which made user have a good experience in web application.

\section{Literature Review}

\subsection{E-Commerce}

E-Commerce or electronic commerce [1] is usually associated with a buying or selling of goods or services. It is an online business activities for product and service. E-commerce is conducted using variety of applications for example, online catalogs, shopping cart or shopping basket, online payment and shipping method.

\subsection{Usability}


Usability is a quality attribute that assesses how easy user interfaces are to use. Usability principle have 5 types of quality components such as: [2]

- Learning ability: How easy is it for users to accomplish basic tasks the first time they encounter the design?

- Efficiency: Once users have learned the design, how quickly can they perform tasks?

- Memorability: When users return to the design after a period of not using it, how easily can they reestablish proficiency?

- Errors: How many errors do users make, how severe are these errors, and how easily can they recover from the errors?

- Satisfaction: How pleasant is it to use the design?

Usability electronics commerce website design have 5 main ideas that is

- Product Focused: When customer needs to find some products in e-commerce website, they should meet their requirement immediately and show clearly content.

- Browsers: This idea focus on browsing product on website. The e-commerce site should show listing of new, popular, recommended and sale products. Customer should easy to access inventory product and share some information which they like.

- Researchers: Researchers is someone who plan to purchase in the future. They are collecting information about products and prices and they going to visit multiple e-commerce site to gather information before committing to a purchase. Therefore, the trust is the key important to them. In this idea should have clearly information and product details. The content should easy to understand and should have user reviews.

- Bargain Hunters: Bargain Hunters is one type of shopper who wants to look for best deal possible. Hence, Designing usability e-commerce website should focus on display sale product, discounts and saving.

- One-Time Shoppers: In this idea recommended to designing clear navigation and complete product descriptions.

Usability e-commerce website design is the route to increase selling for shop and It is a chance for buyer too.

\subsection{Related Work}

Wan Abdul Rahim Wan Mohd Isa, Anitawati Mohd Lokman, Eza Syafiqa A Wahid And Roziah Sulaiman [3] improved Handicraft Web-based system by using usability Testing principle. They have 20 participants between 25 to 40 years old to test the handicraft website. They have fifteen females and five males to test and nineteen of them had experiences to surf internet more than seven years and seventeen of them had experience in online shopping between one to three years. They use questionnaires with usability testing questions which information of handicraft website and counting access time. Furthermore, there are another usability testing paper to improve usability website such as a case study of usability testing by heuristic evaluation a web domain.

This is the paper of Freddy Paz, Freddy A. Paz, Daniela Villanueva, and Jose Antonio Pow-Sang [4]. They have two phase for heuristic and evaluation on HotelClub.com which the hotel web domain.

Célia Ferreira, Ramiro Gonçalves and Rosalina Babo [5] says about the internet and electronic devices in today's far more to it. In this application, the businesses must use all of electronic devices to increase the chances to sale their product. E-commerce use web 2.0 technology, which can be adapted to doing business online and analysis the principle of online businesses to understand how to do business online. He has created a website analysis and comparison sites on those topics, he set up a website where what the user is interested in those sites, which can be adapted to make the site look more attractive. 
Jari-Pekka Voutilainen, Jaakko Salonen and Tommi Mikkonen [6] recommended to use Bootstrap Platform and CKAN Platform for helping web designer to develop templates for support responsive website design.

The paper of Wei Jiang, Meng Zhang, Bin Zhou, Yujian Jiang and Yingwei Zhang [7] support to improve the display of website on variety web browser. They designed website by using bootstrap platform and their result is correctly website display, but on Internet Explorer 8 and 9 cannot show some syntax of Cascading Style Sheets 3.

Emmanouil Perakakis and Gheorghita Ghinea [8] use smart TV which can access the internet to display the website which responsive website design, The smart TV can show the correctly website. Therefore, their recommend to use Jquery Technology and principle of responsive design to designing the website.

\section{Methodology}

\subsection{Designing e-Commerce Website by Using Usability Principle and Responsive Design}

We designed and developed DPU bakery e-commerce web application follow 5 types of quality components of usability principle. At first, we have search engine feature for find products that customer can find product rapidly. Next is browsers, we have a listing of new, popular, recommended and sale product in the site. Then, we input product details and needful information for researchers to collecting data for next time. Next is bargain hunters, we displayed special deal on the homepage for first seen and the last one is one-time shoppers, we have easy navigation for their. Then, we design web application follow responsive design by using bootstrap platform which 3 main features consist of online catalog, shopping cart and payment method. The sample of e-commerce website design by using usability principle and responsive design are shown on Fig. 1.

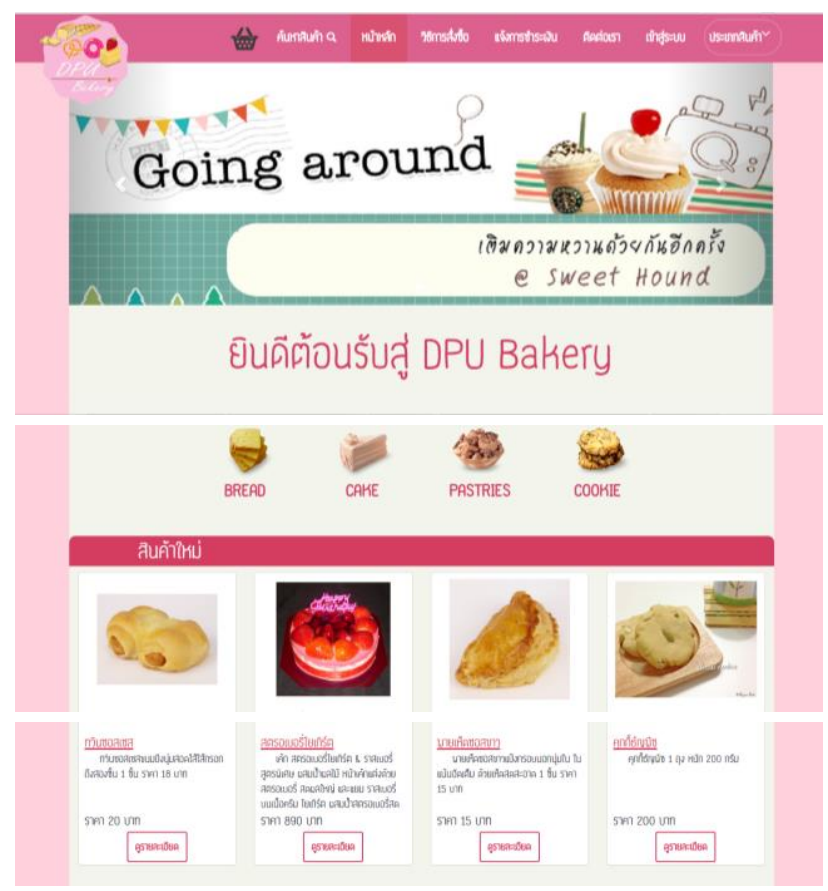

Fig. 1. Responsive e-commerce web application homepage.

\subsection{Designing Questionnaires and Invited 20 Participants to Answer}

The questionnaires have three phases such as first, related of participants' information. Next, behavior of user which time of surf internet and questions for usability testing. After that, we invited 20 participants for 
answer the questions about product, how to order and how to pay money and count time when participants find the answer. The questions of usability design are presented on Fig. 2.

\begin{tabular}{|c|l|}
\hline No. & \multicolumn{1}{|c|}{ Questions/Activity } \\
\hline 1 & How many DPU bakery bank account? \\
\hline 2 & What is the branch of SCB bank account of DPU bakery? \\
\hline 3 & How many type of bakery on DPU bakery website? \\
\hline 4 & Input text (Happy Birthday to you) on caramel toffee cake. \\
\hline 5 & How much of 3 ponds black forest cake? (Answer in Thai baht) \\
\hline 6 & How many day which you can order our bakery before? \\
\hline 7 & What time which you have to inform payment to us when you order our bakery? \\
\hline 8 & What is icon when you want to order our bakery? \\
\hline 9 & What is the telephone number of DPU bakery? \\
\hline 10 & Search for "Cake" on our website and show us for result when search finished. \\
\hline
\end{tabular}

Fig. 2. Questions of usability design.

\subsection{Result of Usability Design Testing}

The participants aged which answer questionnaires between 20 to 30 years old and it is 9 women and 11 men. There are only one of the participants spent time on the internet between 2 to 4 hours, 8 of them spent between 4 to 6 hours, 3 of them surf internet between 6 to 8 hours and 8 spent time more than 8 hours per day on internet. In each question, participant can find the answer of question rapidly.

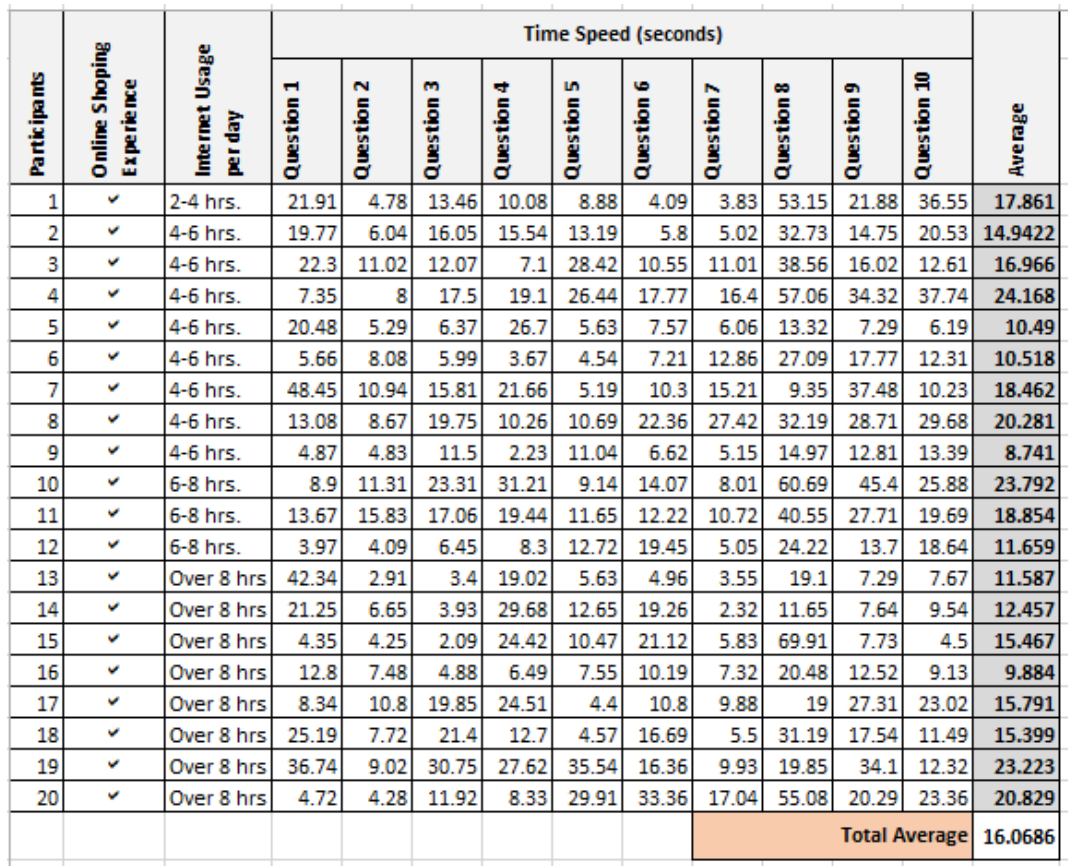

Fig. 3. Result of usability design testing.

\subsection{Web Browser Compatibility Testing}

We use popular web browser on computer to test our responsive e-commerce web application consists of Internet Explorer, Google Chrome and Mozilla Firefox. On mobile devices, we use Mobile Default Browser, Mobile Chrome and Mobile Safari for test compatibility of mobile display. Fig. 4 and Fig. 5 presented the 
result of web browser compatibility testing.

\begin{tabular}{|l|c|c|c|c|c|c|}
\hline \multirow{2}{*}{$\begin{array}{c}\text { Computer Web } \\
\text { Browser }\end{array}$} & \multicolumn{2}{|c|}{ Online Catalog } & \multicolumn{2}{c|}{$\begin{array}{c}\text { Shopping } \\
\text { Cart }\end{array}$} & \multicolumn{2}{c|}{$\begin{array}{c}\text { Payment } \\
\text { Method }\end{array}$} \\
\hline & OK & $\begin{array}{c}\text { Not } \\
\text { OK }\end{array}$ & OK & $\begin{array}{c}\text { Not } \\
\text { OK }\end{array}$ & OK & $\begin{array}{c}\text { Not } \\
\text { OK }\end{array}$ \\
\hline $\begin{array}{l}\text { Internet Explorer } \\
\text { Version 8 }\end{array}$ & & $\times$ & & $\times$ & & $\times$ \\
\hline $\begin{array}{l}\text { Internet Explorer } \\
\text { Version 9 }\end{array}$ & & $\times$ & & $\times$ & & $\times$ \\
\hline $\begin{array}{l}\text { Internet Explorer } \\
\text { Version 10 }\end{array}$ & & $\times$ & & $\times$ & & $\times$ \\
\hline $\begin{array}{l}\text { Internet Explorer } \\
\text { Version 11 }\end{array}$ & & $\times$ & & $\times$ & & $\times$ \\
\hline Microsoft Edge & $\checkmark$ & & $\checkmark$ & & & $\times$ \\
\hline $\begin{array}{l}\text { Google Chrome } \\
\text { Version 46 }\end{array}$ & $\checkmark$ & & $\checkmark$ & & $\checkmark$ & \\
\hline $\begin{array}{l}\text { Google Chrome } \\
\text { Version 47 }\end{array}$ & $\checkmark$ & & $\checkmark$ & & $\checkmark$ & \\
\hline $\begin{array}{l}\text { Google Chrome } \\
\text { Version 48 }\end{array}$ & $\checkmark$ & & $\checkmark$ & & $\checkmark$ & \\
\hline $\begin{array}{l}\text { Mozilla FireFox } \\
\text { Version 42 }\end{array}$ & $\checkmark$ & & $\checkmark$ & & & $\times$ \\
\hline $\begin{array}{l}\text { Mozilla FireFox } \\
\text { Version 43 }\end{array}$ & $\checkmark$ & & $\checkmark$ & & & $\times$ \\
\hline $\begin{array}{l}\text { Mozilla FireFox } \\
\text { Version 44 }\end{array}$ & $\checkmark$ & & $\checkmark$ & & & $\times$ \\
\hline
\end{tabular}

Fig. 4. Computer web browser testing.

\begin{tabular}{|l|c|c|c|c|c|c|}
\hline \multirow{2}{*}{ Mobile Browser } & \multicolumn{2}{|c|}{ Online Catalog } & \multicolumn{2}{c|}{$\begin{array}{c}\text { Shopping } \\
\text { Cart }\end{array}$} & \multicolumn{2}{c|}{$\begin{array}{c}\text { Payment } \\
\text { Method }\end{array}$} \\
\cline { 2 - 7 } & OK & $\begin{array}{c}\text { Not } \\
\text { OK }\end{array}$ & OK & $\begin{array}{c}\text { Not } \\
\text { OK }\end{array}$ & OK & $\begin{array}{c}\text { Not } \\
\text { OK }\end{array}$ \\
\hline Safari & $\checkmark$ & & $\checkmark$ & & $\checkmark$ & \\
\hline Internet & $\checkmark$ & & $\checkmark$ & & $\checkmark$ & \\
\hline Android Chrome & $\checkmark$ & & $\checkmark$ & & $\checkmark$ & \\
\hline Mobile Chrome & $\checkmark$ & & $\checkmark$ & & $\checkmark$ & \\
\hline
\end{tabular}

Fig. 5. Mobile browser testing.

\subsection{Result of Browser Compatibility Testing}

We found responsive e-commerce features cannot work on Internet explorer version 8 to 11 but Microsoft Edge can display only some features like online catalog and shopping cart but it cannot display payment method feature in right format and all version of Mozilla Firefox can display some feature like Microsoft Edge. In Google Chrome Browser, all of version can show correctly all features and in mobile testing, all of mobile browser include Safari, Internet, Android Chrome and Mobile Chrome give the same consequence like Google Chrome Browser that is all of mobile browser can display all of features correctly.

\section{Conclusion and Future Work}

As a result of usability design testing, we found the important things which website designer and developer must consider, at first, they must have the clearly entire navigation because of it will help customers to meet all of store information which their want. Next, they must show details which support all e-commerce features like product details, payment method, order process and delivery method on website. Thus, usability design principle can helped customer buy products from online store easily due to customers can find products and details of them on the store rapidly. Moreover, website designer must focus on cascading style sheets or CSS because that is web design technique for responsive website, especially, CSS3 by the reason of some elements in CSS cannot display on web browser that will made store owner lose opportunity for sales because the customers cannot access website. Therefore, Design step in website development process is the most important.

This article attempted to identify the impact of web usability design in responsive e-commerce web application. Even though the findings provide meaningful implications. At first, the present study was 
limited only to studying on B2C websites. However, non-functional aspects of the website such as pleasure, amusement and emotional fulfillment may be significant and contribute importantly to overall satisfaction.

\section{References}

[1] Kenneth, C., \& Laudon, C. G. T. (2014). E-Commerce: Business, Technology, Society (10th ed.). Prentice Hall: Publisher.

[2] Jakob, N. (2017). Introduction to Usability. Nielsen Norman Group.

[3] Wan, A. R. W. M. I., et al. (2014). Usability testing research framework: Case of Handicraft Web-Based System. Proceedings of the 2nd International Conference on Information and Communication Technology 2014 on Bandung (pp. 199-204). Bandung, Indonesia: IEEE.

[4] Freddy, P., et al. (2015). Heuristic evaluation as a complement to usability testing: A case study in web domain. Proceedings of the 12th International Conference on Information Technology: New Generations on Las Vegas, NV (pp. 546-551). Las Vegas, NV: IEEE.

[5] Célia, F., et al. (2011). Evaluating functionalities of ecommerce websites for emigrants. Proceedings of the 2011 6th Iberian Conference on Information Systems and Technologies (pp. 745-749). Chaves, Portugal: IEEE.

[6] Jari-Pekka, V., et al. (2015). On the design of a responsive user interface for a multi-device web service. Proceedings of the Second ACM International Conference on Mobile Software Engineering and Systems (pp. 60-63). Florence, Italy: IEEE.

[7] Wei, J., et al. (2014). Responsive web design mode and application. Proceedings of the Second ACM International Conference on Mobile Software Engineering and Systems (pp. 1303-1306). Ottawa, ON, Canada: IEEE.

[8] Emmanouil, P., \& Gheorghita, G. (2015). Responsive web design for the internet connected TV. Proceedings of the 2015 IEEE 5th International Conference on Consumer Electronics Berlin (ICCE-Berlin) (pp. 38-42). Berlin, Germany: IEEE.

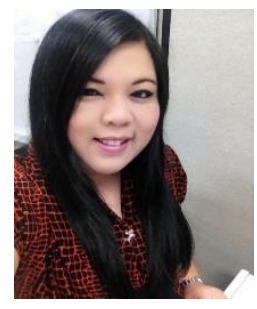

Lalita Santiworarak was born on Wednesday $22^{\text {nd }}$ of November 1978 in Ubonrachathani, province in the north eastern region of Thailand. She graduated with a bachelor of business administration, first class honors, gold medal in business information technology in 2006 from Dhurakij Pundit University, Thailand.

She worked as a lecturer in Information Technology Faculty in Dhurakij Pundit University from 2006 to 2015 . Her teaching areas include e-business theory, applications software (ex. adobe photoshop, illustrator, animate) and web programming (ex. PHP, ASP.Net). Now, she is a website development department manager at Branding Communication Department, Dhurakij Pundit University, Thailand. Her research interests include web usability, web accessibility, website content management and webometrics (ranking web of university).

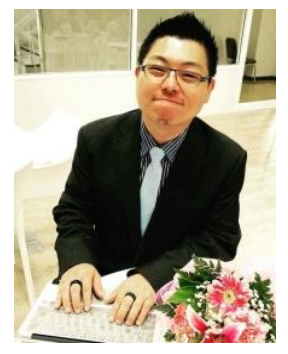

Worasit Choochaiwattana was born in 1975. He earned a B.B.A.(marketing) in 1996 from Chulalongkorn University, Thailand, a M.Sc.(technology of information system management) in 2000 from Mahidol University, Thailand, a M.Sc.(computer science) in 2003 from Chulalongkorn University, Thailand, and a Ph.D.(information science) from University of Pittsburgh, Pennsylvania, United States.

Now, he is an assistance professor at College of Creative Design and Entertainment Technology, Dhurakij Pundit University, Thailand. His research interests include search engines, adaptive web and intelligent information systems. 